\title{
O DESENVOLVIMENTO DO RACIOCÍNIO NA ERA DA TECNOLOGIA: COGNIÇÃO X DOUTRINAÇÃO
}

\author{
EL DESARROLLO DEL RACIOCINIO EN LA ERA DE LA TECNOLOGÍA: \\ COGNICIÓN X ADOCTRINAMIENTO
}

THE DEVELOPMENT OF THE REASON IN THE AGE OF TECHNOLOGY:
COGNITION X INDOCTRINATION

\author{
Maria Angélica Seabra Rodrigues MARTINS ${ }^{1}$
}

RESUMO: A formação de professores no atual universo das tecnologias e a necessidade de se obter alunos capazes de pensar e de pensar por si mesmos, tem sido um desafio constante e difícil de vencer para muitos professores em todos os níveis de ensino. A concorrência da escola com os meios de comunicação, se por um lado facilita a vida do aluno; por outro, afasta-o da possibilidade de pesquisas mais profundas, do contato com uma biblioteca física, uma vez que a superficialidade dos temas oferecidos pela internet muitas vezes assume esse papel, tornando dificultosa a necessidade de desenvolvimento do raciocínio lógico e da própria capacidade de redigir com clareza, coesão e criatividade. Mas, como produzir textos com qualidade, se o aluno não é treinado para exercer a dialética, nem possui conteúdo para tal? As pesquisas que temos desenvolvido nos últimos vinte anos, a partir da preocupação com a qualidade do ensino, baseiam-se particularmente na capacidade do professor de levar o aluno à reflexão, criando uma rede cognitiva que não esteja ligada diretamente a um ensino dogmático, capaz de reduzir sua visão. A reforma do ensino proposta recentemente pelo governo propõe uma escola sem doutrinação, mas muitos professores sentem-se incapazes de encontrar uma forma de auxiliar seus alunos a serem mais críticos e observadores, uma vez que muitos manuais de História, Geografia ou mesmo de Filosofia apresentam uma tendência nitidamente marxista. Como, então, levar o aluno à reflexão, sem que ele seja conduzido por caminhos doutrinários? Como levá-lo a refletir acerca dos problemas com que convive no mundo, de forma a distinguir um pensamento racional de um tendencioso, se o próprio mundo que o cerca, os meios de comunicação, principalmente a Internet, fornecem-lhe bases nitidamente doutrinárias? Neste artigo procuraremos apresentar caminhos que nos foram úteis tanto na formação de professores de Pedagogia, quanto no trabalho com alunos de nível médio, visando o desenvolvimento de sua capacidade de reflexão. Com base na Psicologia (BETTELHEIM, 1980; JUNG, 2008), na Filosofia da Educação (LIPMAN, 1994), na antropologia (ELIADE, 1972; CAMPBELL, 2013) e na Filosofia Clássica (PENHA,1994), apresentaremos nossa abordagem acerca da formação de alunos críticos e questionadores.

PALAVRAS-CHAVE: Raciocínio cognitivo. Doutrinação. Arquétipos. Antropologia. Filosofia da educação

1 Universidade Estadual Paulista (Unesp), Bauru - SP - Brasil. Professora Doutora aposentada do Departamento de Ciências Humanas da Faculdade de Arquitetura, Artes e Comunicação - FAAC/Unesp. E-mail: masrm@uol.com.br 
RESUMEN: Una formación de professores em el universo actual de las tecnologías y una necesidad de aprendizaje de los alumnos de pensar y de pensar por símismos, hay sido um desafío constante y difícil de vencer para muchos professores en todos los niveles de enseñanza. La competencia de la escuela com los médios de comunicación, si por un lado facilita la vida de la lumno, por otro, parece alejarlo de la posibilidad de los más profundos estudios, y de hacer contacto con una biblioteca física. Una vez que una superficialidade de los temas ofrecidos por Internet, muchas veces proponen ese papel, convirtién dose difícil la necesidad de desarrollo de um raciocinio lógico y de la propia capacidad de redactar contransparencia, cohesióny criatividad. Pero, ¿Como producir textos com calidad, se el alumno no está entrenado para ejercer uma dialéctica, y no tiene contenido para tal? Las investigaciones que hemos desarrol lado em los últimos veinteaños, a partir de la preocupación por la calidad de la enseñanza, se basan particularmente em la capacidade del profesor de llevar al alumno a la reflexión, creando una red cognitiva que no este ligada directamente a una enseñanza dogmática, capaz de reducir su visión. La reforma de la enseñanza propuesta recientemente por el gobierno propone una escuela sina doctrinamiento, pero muchos profesores se sientenin capaces de encontrar una forma de ayudar a sus alumnos a ser más críticos y observadores, ya que muchos manuales de Historia, Geografía o incluso de Filosofía presenta numa tendência nítidamente marxista.¿ Cómo, entonces, llevar al alumno a la reflexión, sinque élsea conducido por caminhos doctrinarios? ¿Cómo llevarlo a reflexionar acerca de los problemas conque conviveenel mundo, para diferenciar um pensamiento racional, de un tendencioso, si el próprio mundo que lo rodea, los medios de comunicación, principalmente la internet, leproveen bases nitidamente doctrinales? En este artículo buscaremos presentar caminos que nos fueronútiles tanto em la formación de profesores de Pedagogía, cuanto em el trabajo com alumnos de escuela intermedias, buscando el desarrollo de su capacidad de reflexión. En la psicología (BETTELHEIM, 1980, JUNG, 2008) en la Filosofía de la Educación (LIPMAN, 1994), en la antropología (ELIADE, 1972; CAMPBELL, 2013) y en la Filosofía Clásica (PENHA, 1994), presentaremos nuestro enfoque sobre la Formación de alumnos críticos y cuestionadores.

PALABRAS CLAVE: Raciocinio cognitivo. Adoctrinamiento. Arquetipos. Antropología. Filosofía de la educación

ABSTRACT: The teachers education in the current universe of technologies and the need to obtain students capable of thinking and thinking for themselves has been a constant challenge and difficult to overcome for many teachers at all levels of education. The competition of the school with the media, if on one hand helps the student's life; On the other hand, it puts them away from the possibility of deeper researches, from contact with a physical library, since the superficiality of the themes offered by the Internet often assumes this role, making difficult to develop logical reasoning and their own capacity to write with clarity, cohesion and creativity. But how can we produce quality texts if the student is not trained to exercise the dialectic and does not have content to do them so? The researches which have been developed by us over the last twenty years, based on the concern with the quality of teaching, are based in particular on the teacher's ability to lead the student to reflection, creating a cognitive network that is not directly linked to dogmatic teaching, which is capable to reduce their vision. The educational reform recently proposed by the government proposes a school without indoctrination, however, many teachers feel incapable of 
finding a way to help their students to be more critical and observant, since many History, Geography or even Philosophy manuals present a clearly Marxist tendency. How to lead the student to reflection, without being led by doctrinal paths? How to get him to reflect on the problems in which he lives in, in order to distinguish a rational thought from a biased one, if the world around him, the media, especially the internet, provides him with clearly doctrinal bases? In this article we will try to present ways that either was useful for the formation of Pedagogy teachers or in the work with high school students, aiming the development of their capacity for reflection. Based on Psychology (BETTELHEIM, 1980; JUNG, 2008) in the Philosophy of Education (LIPMAN, 1994), in the anthropology (ELIADE, 1972; CAMPBELL, 2013) and in the Classical Philosophy (PENHA, 1994), we will present our approach to training critical and questioning students.

KEYWORDS: Cognitive reasoning. Indoctination. Archetypes. Anthropology. Philosophy of education.

\section{Introdução}

Desde seus primórdios, a organização do homem em sociedade envolveu a busca por explicações para o que ocorria a sua volta, como os fenômenos da natureza, a vida e a morte. Todas as culturas do mundo desenvolveram seus mitos como forma de explicar esses fenômenos, atribuindo-os ao sobrenatural. Assim surgiram os mitos, sendo que os homens estavam sujeitos a seres poderosos, que determinavam a ocorrência de terremotos, maremotos, tempestades, secas ou inundações, a seu bel prazer. Ou seja, o homem era mero instrumento da ação dos deuses temperamentais que ele mesmo construíra, à sua imagem e semelhança. Segundo Eliade (1972), as histórias acerca de como tudo ocorreu no mundo eram consideradas sagradas e verdadeiras, pois delas participavam os deuses. Dessa forma, surgiram os rituais que visavam aplacar a ira desses seres, garantir uma boa colheita, chuvas adequadas e ausência de doenças. Os mitos que marcavam todas as civilizações eram, primordialmente, os cosmogônicos, que explicavam como tudo surgiu; e os escatológicos, que esclareciam como tudo iria terminar. Como a Bíblia também é um meio de narrar a história de um povo, o judeu, os mitos surgem nessas narrativas consideradas sagradas, como no Gênesis, em que é apresentada a criação do mundo, enquanto no Apocalipse há um detalhamento acerca de como o mundo irá terminar. Além desses mitos, também havia aqueles em que um herói interveio para salvar um povo, muitas vezes com o risco da própria vida.

Em muitas das culturas esses mitos se assemelham, diferindo apenas em alguns detalhes, mas todos possuíam seu panteão mitológico e seus heróis, fossem gregos, 
romanos, celtas, astecas, nórdicos ou africanos. Em comum a reverência aos deuses, os rituais, celebrados em ocasiões especiais -- como na introdução do jovem à vida adulta, para que assumisse as responsabilidades para com sua tribo - por um ancião ou xamã, geralmente no inverno, em uma caverna, ao redor de uma fogueira. Apesar de também existirem as histórias que faziam parte do anedotário, não sagradas, que poderiam ser narradas em qualquer época, tempo e lugar, também presentes em todas as culturas.

Com o surgimento da filosofia especulativa, em torno do século VI, antes de Cristo, o mito começa a ser questionado, em um momento em que o ser humano sente a necessidade de encontrar respostas racionais para o que ocorria no universo, a partir das respostas para as clássicas perguntas: “quem sou?", “de onde vim?”, “como tudo se formou”? As chamadas “escolas” (jônica, eleática, atomística e itálica) determinavam a linha de raciocínio dos grupos de filósofos e sua preocupação com o desvendar o segredo do "kosmos", ou seja, como tudo se organizara e surgira, após um "kaos" inicial. Eram os chamados filósofos pré-socráticos. Somente a partir de Sócrates, depois Platão e Aristóteles, a filosofia passa a se voltar para o interior do ser humano.

Com o advento do cristianismo no século I, a filosofia especulativa foi gradativamente sendo negligenciada, sendo substituída pelos dogmas da nova religião que se espalhava por todo o mundo conhecido. Entretanto, o gosto do ser humano pela narração permaneceu, quer nos textos da Bíblia, quer na narrativa oral, retomando o feito de grandes heróis do passado, como Ulisses, Hércules e dos cavaleiros medievais que partiram para as inúmeras guerras e para as Cruzadas, e a saga do Rei Artur e seus cavaleiros, mesclando elementos do cristianismo e das lendas celtas, sendo que a do Santo Graal, protagonizada por Sir Galahad, o último e mais puro dos cavaleiros da Távola Redonda, torna-se conhecida em todo o mundo.

Muitas das narrativas orais que surgiram ao longo de toda a Idade Média eram levadas pelos menestréis através dos reinos, sendo adaptadas ao gosto local. Em comum, essas histórias tinham um fundo moral e não eram especificamente destinadas às crianças, a quem pouco valor se atribuía, uma vez que devido à grande mortandade infantil, os próprios pais pouco se apegavam aos filhos. Séculos após, entretanto, a psicanálise ressalta sua importância, uma vez que essas histórias de tempos imemoriais falam ao ego em formação da criança, atuando sobre seu inconsciente coletivo, determinando valores que são captados em um nível subliminar - o do "lá-então"que, ao serem trazidos para o "aqui-agora" pela criança, leva-a a introjetar os valores assimilados no mundo de fantasia do "Era uma vez...". 


\section{Os contos de fada e a formação da criança}

Muitas das histórias da narrativa oral surgem sob diferentes aspectos, em diferentes épocas, adaptadas ao gosto local. Assim, há uma Cinderela que surgiu na China, oitocentos anos antes de ser conhecida no Ocidente, bem como muitas versões dessa mesma e de várias outras histórias, adaptadas ao gosto da época e da cultura locais. No século XVII, Charles Perrault reuniu essas narrativas captadas do trato oral em uma publicação de 1695, denominada Histoires ou contes dutempspassés, avecdesmoralités ("Histórias ou contos de tempos passados, com moralidades"), que ficou mais conhecido pelo subtítulo Contes de mamèrel'Oye ou "Contos da Mamãe Gansa”, amplamente divulgadas nos salões parisienses da época.

No século XIX, os Irmaõs Grimm, na região que hoje pertence à Alemanha, em um estudo acadêmico propuseram-se a rever as histórias de Perrault e outras narrativas populares, que foram publicadas sob a ótica da igreja luterana, com o propósito de serem utilizadas como transmissoras de valores às crianças, nas escolas mantidas por elas. Dessa forma, os seres sobrenaturais como fadas, bruxas, duendes, que surgiam nas histórias antigas, foram substituídos por seres ou situações que estivessem de acordo com as normas do luteranismo, adquirindo um caráter religioso. Assim, se na Cinderela de Perrault havia uma fada madrinha que atendia aos requisitos da borralheira para ir ao baile, na narrativa dos Irmãos Grimm ela é substituída por forças da natureza e por pombinhas (símbolo do Espírito Santo), que atendem à menina, quando ela ora no túmulo da mãe, declarando o desejo de poder ir à festa.

Observa-se que ocorre uma identificação da criança com o herói das narrativas, com o qual vive as aventuras, sofre e triunfa no final, o que permite aos pequenos trazerem, em um nível inconsciente, essas vivências para sua própria vida, auxiliando-as a solucionar seus próprios problemas e a assimilar os valores transmitidos.

\section{A psicologia nos contos de fada}

Bruno Bettelheim, psicólogo austríaco e discípulo de Freud, preso em 1938 e enviado pelos nazistas aos campos de concentração de Dachau e Buchenwald, pôde observar in loco crianças traumatizadas pelos horrores da guerra. Ao ser libertado em 1939, imigrou para os Estados Unidos, tornando-se professor universitário. A publicação de seu artigo Individual and Mass Behaviour in Extreme Situations (1943) 
tornou-o conhecido, principalmente por seu trabalho com crianças vítimas de distúrbios emocionais graves, principalmente as autistas.

Foi um dos especialistas que mais se debruçou sobre o estudo da influência dos contos de fada. Para ele a grande diferença entre este tipo de contos e os modernos é que os primeiros, ao contrário dos segundos, não remetem apenas para o encantamento, tratando também de problemas existenciais, algo que permanece inalterável com a passagem do tempo. ${ }^{2}$

A esse respeito, Maria Tatar (2004), acadêmica norte-americana, estudiosa da literatura infantil e do folclore alemão, esclarece que "nossos desejos mais profundos, bem como nossas angústias mais arraigadas misturam-se ao folclore e nele permanecem através de histórias que ganham a predileção de uma comunidade de leitores ou de ouvintes" (2004, p. 10).

Sob a ótica da psicanálise, Bettelheim e outros de sua linha de pesquisa acreditam que esses contos possuem um grande valor terapêutico, ao ensinar às crianças sobre a luta contra as dificuldades da vida, e que esses contos apresentam ao indivíduo situações em que surgem sofrimentos inesperados e que devem ser enfrentados resolutamente, para que no final se alcance a vitória. Ao encontrar nessas histórias ecos para seus próprios problemas, o ouvinte harmoniza-as com suas ansiedades e aspirações, encontrando possíveis soluções para seus perturbadores problemas; dessa forma, firma-se uma base para o desenvolvimento do raciocínio psico-cognitivo e a formação global do indivíduo.

A literatura infantil em geral, afirma o psicanalista, procura divertir ou informar a criança, mas muitos livros são tão superficiais que pouco significado podem ter para sua formação, uma vez que a aquisição de habilidades, inclusive a da leitura, fica prejudicada, quando o que se aprendeu a ler nada acrescenta de importante à vida. (BETTELHEIM, 1980, p.12).

Uma boa estória, segundo Bettelheim (1980), deve estar relacionada a todos os aspectos da personalidade dos pequenos, sem os menosprezar, enfatizando o âmbito positivo e auxiliando-os a promover a confiança em si mesmos e no futuro. A forma e a estrutura dos contos de fadas sugerem imagens à criança, a partir das quais ela pode estruturar seus devaneios, direcionando melhor sua vida. Considerando o modelo psicanalítico de id, ego e superego, os contos de fada (folclóricos), enfocando

${ }^{2}$ Disponível em: <http://www.dec.ufcg.edu.br/biografias/BrunoBet.htm>. 
problemas humanos universais, particularmente os que preocupam as crianças, falam ao ego em germinação, e encorajam seu desenvolvimento (Bettelheim, p.14), enquanto aliviam pressões pré-conscientes e inconscientes. Dessa forma, à medida que a narrativa se desenvolve, surgem elementos capazes de auxiliar a criança a entender as pressões do id, oferecendo possíveis soluções (de acordo com os requisitos do ego e do superego) temporárias ou permanentes, para problemas que a perturbam.

Uma das críticas de Bettelheim (1980) às estórias modernas é que elas evitam mencionar os problemas existenciais (morte, envelhecimento, desejo de vida eterna, os limites da existência), embora, ao preservar a criança dessa forma, impeçam que alcance a maturidade com segurança:
Ao contrário do que acontece em muitas estórias infantis modernas, nos contos de fadas o mal é tão onipresente quanto a virtude (...) o bem e o mal recebem corpo na forma de algumas figuras e de suas ações, já que bem e mal são onipresentes na vida e as propensões para ambos estão presentes em todo homem (...) dualidade que coloca o problema moral e requisita a luta para resolvê-lo (Ibidem, p. 15)

A escolha entre o bem e o mal não se prende ao fato de o primeiro sempre vencer no final, mas sim porque a identificação com o herói é mais atraente para a criança, que reconhece a si mesma nesse personagem, projetando-se em suas lutas e dificuldades; dessa forma, sofre também com as provas e tribulações do personagem, triunfando com ele quando alcança a vitória. No decorrer desse processo, uma mensagem moral subliminar é transmitida e ela opta por escolher o bem, em virtude de se projetar na figura do herói: - se esta figura é uma pessoa muito boa, então a criança decide que quer ser boa também (BETTELHEIM, 1980, p.18), para parecer-se com ele, fazendo uma escolha na vida, sendo que a escolha moral permite-lhe uma inserção adequada no meio social. Também o felizes para sempre permite que ela observe que após lutar contra muitos obstáculos, adquire segurança emocional suficiente para permanecer ao lado de alguém e vencer, construindo uma relação satisfatória, sem precisar experimentar a ansiedade da separação, ao mesmo tempo que aprende a abandonar seus desejos de dependência infantil, conseguindo, no futuro, ser um adulto menos ansioso e mais independente.

Segundo Carl Jung (cf. SILVEIRA, 1978), outro psicanalista, o indivíduo agrega um consciente, um inconsciente individual e um inconsciente coletivo, sendo que neste último estão situadas as imagens arquetípicas presentes nos contos de fada (bruxas, 
fadas, duendes, magos), as quais constituem elementos importantes para fixar a imaginação infantil em dados já conhecidos há muitas gerações. Seus antepassados já teriam tido conhecimento dessas imagens, por meio de histórias contadas pela narrativa popular, que foram passando através de gerações, e que também atuam como forma de aceitação: "o conto de fadas é a forma imaginária que os problemas humanos mais ou menos universais alcançaram à medida que a estória passou por gerações" (BETTELHEIM, 1980, p.74)

Uma outra questão a se considerar é que a criança capta as informações transmitidas pelos contos, que de uma forma subjetiva, por meio das situações que envolvem os personagens, constitui uma lição muito mais eficiente que se transmitida por meio de um discurso objetivo e denotativo.

Para Bettelheim "as explanações realistas são usualmente incompreensíveis para as crianças, porque lhes falta a compreensão abstrata requerida para que façam sentido para elas" (Idem, p.61). Também as ilustrações devem ser mínimas, não coloridas, para que a criança consiga desenvolver sua própria imaginação, ao invés de captar simplesmente a ideia do ilustrador.

A necessidade da fantasia estaria relacionada ao fato de a criança possuir um ego frágil, em processo de construção; dessa forma, deve visualizar em um contexto exterior a ela os desejos que não consegue dominar, a fim de que possa obter algum tipo de controle sobre eles (BETTELHEIM, 1980, p.71). Certos aspectos de sua vida cotidiana, como a rivalidade entre irmãos ou a dificuldade de convivência com a madrasta (ou com a mãe), vivenciada por certas meninas, por exemplo, estariam reproduzidas nesses contextos, e o fato de observarem que tudo acaba bem fornece-lhes a segurança necessária para aceitar melhor o presente e depositar esperanças no futuro.

A mescla dos fatos narrados com elementos arquetípicos (bruxas, fadas, duendes) produz o efeito de sentido de verdade que para a criança é aceito como - real. Da mesma forma, o contato com as situações vivenciadas pelas personagens reflete contextos em que ela mesma poderá estar inserida, levando-a a se identificar com tais estórias e personagens e a estabelecer um forte elo. A estória de João e Maria é exemplo clássico, pois em um mundo em que os divórcios são frequentes, como o atual, e de famílias reconstruídas sob outros moldes, surge a possibilidade de contato com a madrasta que, se não for bem elaborada, poderá despertar na criança o desejo de fuga, como o apresentado pelos irmãos na história. Da mesma forma, o conto de Branca de Neve, na versão dos Irmãos Grimm, mostra uma adolescente envolvida com sensações 
típicas dessa fase, em conflito com a madrasta (ou com a mãe) pelo amor do pai, em um claro exemplo do Complexo de Édipo (ou de Elektra, para meninas).

Um bom professor deveria estimular a leitura dos clássicos da literatura universal (uma vez que todos estão conectados) e discuti-los com seus alunos, sem que haja uma doutrinação, mas uma explicação clara acerca dos porquês de certas atitudes serem adotadas em determinada época, como no conto "A donzela que não tinha mãos", dos Irmãos Grimm; ou "Chapeuzinho Vermelho" de Perrault, pois um bom educador necessita estar preparado para CONTEXTUALIZAR o que irá oferecer ao aluno, prestando os esclarecimentos necessários acerca de costumes e época, a fim de que a reflexão não seja um caminho de doutrinação, mas de esclarecimento.

\section{As histórias de magia na era da tecnologia}

Nas últimas décadas, a mídia audiovisual tem dominado o mercado de produtos destinados ao entretenimento e à literatura, afetando jovens e crianças. Os jogos eletrônicos são lançados simultaneamente aos sucessos produzidos pelo cinema e pelas grandes redes de televisão. A linha editorial, visando ao lucro, de certa forma negligenciou os livros que levaram gerações à reflexão, como as obras de Grimm, Perrault, Andersen, as Histórias da Carochinha, sendo que até mesmo a leitura das obras de Monteiro Lobato, um ícone para gerações no Brasil no século XX, nos últimos vinte anos foi gradativamente abandonado; muitas das crianças atuais conhecem a boneca Emília, o Visconde de Sabugosa e as crianças livres e felizes, brincando em contato com a natureza, como Pedrinho e Narizinho, apenas por meio dos seriados produzidos pela Rede Globo de Televisão, não necessariamente fieis a Lobato, mas ao massmedia.

Um outro agravante para o afastamento da leitura dos clássicos originais surgiu através do cinema, com as animações produzidas por Walt Disney, a partir do final da década de 1930. Unindo-se ao macartismo que grassou nos Estados Unidos no pós Segunda Guerra Mundial, criou um mundo de fantasia a partir das histórias dos Irmãos Grimm, cujo único propósito era a propaganda norte-americana de um mundo feliz, em contraposição à ameaça comunista oriunda da ex-URSS e depois de Cuba, no período da chamada Guerra Fria. Dessa forma, seus estúdios passaram a produzir filmes que primavam pela beleza visual e acústica, mas que pouco ou nenhum efeito exerceriam no ego infantil em formação, caso se comparasse suas histórias com os originais de Grimm e de Perrault, uma vez que Disney aboliu de suas histórias todos os aspectos que sua 
ideologia considerava "preocupantes", como a morte, o sofrimento sem fim, a vida eterna, o triunfo da maldade, a vingança, o incesto, temas que poderiam causar desequilíbrio em seu pretenso "mundo perfeitamente feliz". Com enorme sucesso de marketing e de vendas, o império Disney fez com que os livros de contos de fada dos Irmãos Grimm e de Perrault praticamente desaparecem das grandes livrarias.

O colorido, os desenhos bem elaborados e os textos mínimos dos novos livros, fizeram com que a criança, fascinada por esse tipo de leitura, também deixasse de procurar obras com textos maiores e com mais conteúdo, dentro da norma culta. $\mathrm{O}$ resultado foram crianças e adolescentes que mal podiam elaborar um raciocínio, devido ao restrito número de palavras assimiladas, à ausência da lógica em seus pensamentos e à capacidade de redigir com coesão e coerência, incapazes de desenvolver uma linha retórica persuasiva.

Uma retomada da magia estabelecendo a intertextualidade com os contos celtas e os contos de fada originais na literatura infanto-juvenil, contudo, surge em 1997 (2001, no Brasil), com a inglesa J. K. Rowlings e seu bruxinho Harry Potter, cujas histórias - escritas em brochuras com poucas gravuras - tornaram-se um fenômeno de vendas no exterior e no Brasil. Similar ao que recomendava Bettelheim (1980), as histórias possuíam elementos da tradição céltico-bretã, que a criança inglesa, primeiramente, poderia reconhecer, não abolia elementos "preocupantes", como os chamados "dementadores", presentes nas histórias; além de trabalhar a luta entre o Bem e o Mal, personificada dentro do próprio mundo da magia.

Uma criança que escapara ao assassinato de seus pais e que fora negligenciada e maltratada pelos tios, similar a elementos de outros contos de fada, como o de Cinderela, repentinamente torna-se o herói que deve vencer o grande vilão, Voldemort. Os livros, lançados em número de sete, ao longo de dez anos, prenderam a atenção de toda uma geração, que também acompanhava nos filmes, lançados após os livros (o que permitia uma boa leitura anterior), as dificuldades e peripécias do protagonista e seus amigos fiéis, tanto no mundo do "aqui-agora" (onde pouco ficavam), quanto no do "láentão" (em Hogwarts e adjacências), locais onde toda a trama se desenrolava.

Embora críticos como A. S. Byatt, do The New York Times ${ }^{3}(07 / 07 / 2003)$ tenham acusado Rowling de ter elaborado uma colcha de retalhos inteligente de ideias recolhidas de todo o tipo de literatura infantil, o próprio jornalista reconhece que as

3 The New York Times, 07/07/ 2003 
histórias, no âmbito dos estudos culturais, interessariam tanto pelo êxito e pela popularidade, como pelo mérito literário. ${ }^{4}$

Ocorre que a autora, uma professora de Língua Inglesa, empregou de forma criativa a intertextualidade, termo criado por Julia Kristeva, contemporânea de Roland Barthes e estudiosa de Mikhail Bakhtin; voltando-se para questões de produtividade do texto, Kristeva acreditava que "Qualquer texto se constrói como um mosaico de citações e é absorção e transformação de outro texto", conforme publicou na Revista TEL QUEL (Poética no. 27, p. 45-53). Ou seja, um texto é um ponto de cruzamento de vários outros textos, retomados e ampliados, modificados segundo a criatividade do autor. Em Harry Potter surgem vários elementos do mundo das lendas bretãs, como bruxas, feitiços, seres dos mitos, como o Hipogrifo, que já surgira em lendas gregas e, inclusive, também está presente na capa da primeira edição de "Alice no País das Maravilhas", de Lewis Carroll, em 1865; ou o Basilisco, a serpente símbolo do Mal, que surge em vários poetas da Idade Média e em autores como Jonathan Swift, Voltaire, em obras do poeta Shelley, entre outros.

Se analisados sob a ótica de Bettelheim (1980), os textos apresentavam uma linguagem adequada, com o predomínio da norma culta, além da retomada da busca de significados e da necessidade de magia. Se comparados aos contos de fada tradicionais, ainda que, conforme apontava outro crítico, Harold Bloom, do The Boston Globe (em 24/9/2003) "contivesse clichês", os livros de J.K. Rowling sobre Harry Potter possuem um ponto inegavelmente positivo, que é o de trazer as crianças de volta aos textos bem escritos, longos, capazes de trabalhar sua imaginação e sua capacidade criativa, remetendo ao inconsciente coletivo e conduzindo o leitor a identificar-se com os personagens e situações apresentadas.

Dessa forma, Harry Potter e suas peripécias colaborou para despertar nos pequenos também o interesse pelos outros contos de magia como os de Grimm e de Perrault, que foram novamente lançados, no formato dos livros da autora, como os "Contos de Fadas", da Editora Zahar, de 2004 (entre os de outras editoras), tanto no formato para crianças, em edição de bolso, como em edição ampliada e com comentários, para professores, mas com ótimo acabamento e seguindo os padrões de boa escrita e poucas gravuras, mantendo espaço para a imaginação da criança. Na mídia virtual também foi lançado um site interativo, o "Pottermore", que permitia às crianças

${ }^{4}$ Idem 
interagirem com as histórias dos livros e dos filmes, por meio de jogos, perguntas e respostas, que as remete à retomada da leitura.

A busca pelo herói e suas peripécias trouxe de volta o caminho através do mito. Em 2010, os estúdios Disney, seguindo a nova tendência, lançaram "Alice no País das Maravilhas", com direção de Tim Burton, que apresentou uma nova leitura da animação de Disney de 1951 (adaptada do livro de Lewis Carroll, de 1865), ao mostrar a ótica do ser humano do século XXI acerca do tolhimento da mulher do século XIX, obrigada a um casamento arranjado e que foge para a "toca do coelho", seu mundo interior, para rever seus valores e exterminar seus medos, representados na figura do temível jaguadarte, o dragão dos tempos medievais.

\section{Os contos de fada e o questionamento filosófico}

O trabalho com a criança a partir dos contos de fada originais, adequados a sua idade, desenvolve sua capacidade de raciocinar e de solucionar problemas, ao retornar ao "aqui-agora". Um bom professor que tenha trabalhado um texto original e esclarecido as situações e personagens com que elas se depararam, relacionados a uma determinada época, em que as coisas aconteciam daquela forma, fará com que a criança questione o "aqui-agora", a partir do que é veiculado pela mídia, e esteja preparada para diferenciar o certo do errado; o ético do não ético; o Bem do Mal, enfim. Ou seja, esse caminho traçado já a preparou para as questões filosóficas com que irá se deparar em um nível mais avançado, estudando desde os pré-socráticos, as ideias de Sócrates e seus discípulos (Platão e Aristóteles), a verdade e a mentira a partir dos sofistas e os pensadores que o auxiliarão a repensar o mundo a seu redor.

O herói dos contos de fada será encontrado dentro de si mesmo, a partir de sua capacidade de raciocinar e de verificar o mundo ao seu redor de maneira crítica, tornando-se mais capaz de captar um raciocínio doutrinário de um que não seja dotado de "sua própria" lógica.

Hélio Schwatzman, filósofo e jornalista brasileiro, aponta que

Um bom professor, daqueles dignos de ser chamados de mestre, é o que leva o aluno a questionar tudo, até a ideia de que tudo deve ser questionado [...]. O bom professor, mesmo que não se recuse a revelar o que pensa sobre temas sensíveis como política, religião [...] já evita, 
"exofficio", recrutar seguidores $5[. .$.$] . Vou um pouco mais longe e$ afirmo que, idealmente, a escola pública deveria ser laica e tão neutra quanto possível, em relação a ideologias e visões de mundo. (Idem).

Dessa forma, ao criticar falhas no projeto de lei, também aponta uma adotada pelo estado de Alagoas de que o professor deveria "abster-se de introduzir conteúdos que possam estar em conflito com as convicções morais, religiosas ou ideológicas dos estudantes ou de seus pais ou responsáveis" (Ibidem). Ora, se não for o professor aquele que traz novos raciocínios, novas ideias capazes de gerar questionamento, como pode o aluno ser capaz de observar um raciocínio bom de um não lógico? Seguir essa regra apresentada por Alagoas seria uma forma de permitir que o aluno traga doutrinações de caráter religioso, ou de uma moral duvidosa, ou ainda um outro que contrarie a ética, sem que possa ter a capacidade de observar as contradições.

No encaminhamento das ideias pode ocorrer a possibilidade de doutrinação por parte do professor, caso atribua a um pensamento o caráter de verdade absoluta, e, portanto, isenta de erro, segundo Reboul (1980), uma vez que poderiam imperar os sofismas, na ausência de espírito crítico por parte do aluno. Torna-se necessário, portanto, "portar-se com a maior neutralidade possível, embora traços ideológicos escapem, por vezes, à filtragem da imparcialidade" (MARTINS, 2007, p. 95)

\section{O professor e a doutrinação}

Em relação ao conceito de doutrinação há muitas controvérsias mas, geralmente,a doutrinação está ligada a termos como ensino, instrução, aprendizado e também a termos pejorativos como perversão, desonestidade, imoralidade,injustiça e manipulação. Doutrinação também está associada a um ensino no qual se objetiva convencer o aluno de um ponto de vista. (VERGARA et alii, 2005, p.178)

Modernamente, a doutrinação é tratada por dois pensadores: Ivan Snook (1974) e Olivier Reboul (1980). Para o primeiro, a doutrinação envolve "uma relação pessoal entre doutrinador e doutrinado" (VERGARA et alii, 2005, p.178), sendo que o autor “critica a verificação da existência de doutrinação a partir do método de ensino, com base na análise, no conteúdo ensinado e nas consequências do ensino, defendendo a intenção como o único critério aceitável" (Idem). Vergara et alii (2005) apontam a ótica de Reboul (1980) sobre o assunto, de que "ninguém doutrina voluntariamente e que o

${ }^{5}$ Disponível em: <http://www1.folha.uol.com.br/colunas/helioschwartsman/2016/05/1773190-o-bomprofessor.shtml>. 
método e o conteúdo devem ser considerados na compreensão do que é doutrinação" (Ibidem), considerando se a escola estaria "a serviço da classe dominante", ou se funcionaria como um "aparelho ideológico do Estado", muito embora a doutrinação possa ocorrer sem que haja a intenção do professor de o fazer. Para analisar a doutrinação efetiva, Reboul (1980) elenca treze passos (cf. Vergara et alii, p. 181-183):

01. Ensinar doutrina perniciosa: "doutrinam-se crianças quando lhes ensinam que seus concidadãos amarelos ou negros são preguiçosos, ladrões e cruéis devido às suas raças";

02. Utilizar o ensino para fazer propaganda partidária: "a doutrinação ocorre quando a propagação de uma opinião partidária se faz em lugar não destinado a isso, principalmente na escola", neste caso ocorreria abuso de poder do docente "em proveito de uma causa ou de um partido";

03. Fazer aprender sem compreender aquilo que deveria ser compreendido: a catequização, ou seja, "ensinar a resposta em vez de explicá-la ou ensinar os meios de encontrá-la”;

04. Utilizar, para ensinar, o argumento de autoridade: não se concede ao aluno a possibilidade de descobrir algo por si mesmo ou de questionar, mas de "acreditar em algo somente porque determinada autoridade falou";

05. Ensinar com base em preconceitos: um ensino baseado em preconceito é, por definição, tendencioso, seja de natureza racista ou nacionalista. "A doutrinação incide aqui no conteúdo e não na forma". Era o que fazia o nazismo, por exemplo, ao pregar a inferioridade de todas as raças que não fossem a ariana.

06. Ensinar com base numa doutrina como se fosse a única possível: um professor doutrina, ao procurar "convencer de que seu modelo é o único válido. A doutrinação não é ensinar uma doutrina, mas prender-se a ele e desprezar as outras";

07. Ensinar como científico aquilo que não o é: "Um exemplo é o hitlerismo, que pretendia ensinar um 'racismo científico' $[. .$. também se enquadram nesse tópico o "socialismo científico", "moral científica "e "explicações científicas da guerra";

08. Não ensinar senão os fatos favoráveis à sua doutrina: excluir o questionamento, aceitando apenas os pontos favoráveis a sua ótica é um exemplo de doutrinação;

09. Falsificar os fatos para apoiar a doutrina: este é um exemplo de ensino tendencioso e mentiroso, em que "o doutrinador inventa fatos, distorce estatísticas, fabrica testemunhos e falsifica"; 
10. Selecionar arbitrariamente esta ou aquela parte do programa de estudos: enfatizar determinada parte de um programa de ensino pode conduzir ao erro, como no caso de um professor de Geografia que ensina apenas acerca do Ocidente, como de se fosse o exemplo perfeito de civilização;

11. Exaltar, no ensino, determinado valor em detrimento dos outros: um exemplo claro ocorre em certos países europeus, onde houve a chegada de grande número de refugiados oriundos das guerras no Oriente Médio, que passaram a ser tratados como indivíduos menos capazes, muito embora no contingente estivessem médicos, advogados, arquitetos etc.

12. Propagar o ódio por meio do ensino: no mundo europeu e norteamericano de hoje, que se sente ameaçado pelo terrorismo, há uma tendência a denegrir a imagem do muçulmano, como se todos fossem terroristas, sendo que a escola não escapa a esses valores;

13. Impor a crença pela violência: Neste caso, o indivíduo é colocado em uma situação tal, que perde a capacidade de refletir; passando a crer somente naquilo em que querem que acredite. Um exemplo claro dessa "lavagem cerebral" aconteceu com muitos alemães durante a Segunda Guerra Mundial, quando Hitler e a propaganda nazista incutiram a falácia da "supremacia da raça ariana", que dominou, sobretudo, a mente dos jovens da chamada "Juventude Hitlerista".

Para Snook (1974, cf Vergara, 2005, p.180), se um professor fascinar seus alunos levando-os a crer em uma proposta, sem que haja a intenção de o fazer, não haverá doutrinação. Entretanto, não se pode negligenciar o fato de que:

Enquanto a educação se relaciona com libertação de capacidades e interesses de toda a personalidade humana, com o ensino baseado na compreensão, a doutrinação se relaciona com o controle e a limitação do indivíduo e com o ensino pernicioso, preconceituoso ou tendencioso. (VERGARA, 2005, p.184)

\section{Ensinar a pensar}

Para que se minimize o risco da doutrinação, a proposta que defendemos é a do estímulo do questionamento e do raciocínio. Lipman (1994), na linha da Filosofia da Educação, acredita que o "o ato de pensar é natural no ser humano, mas pode ser aperfeiçoado por meio de recursos da lógica, tornando os indivíduos mais críticos e questionadores" (MARTINS, 2010, p. 113): 
A habilidade de raciocinar conduz a criança a pensar de forma mais significativa, possibilitando-lhe a obtenção de um conjunto mais rico de inferências lógicas ou linguísticas, através da leitura, ou do que percebe ou experimenta, segundo Lipman (1994). Crianças com problemas de leitura também apresentariam problemas para pensar, pois "a leitura e o pensamento são interdependentes (...) e as crianças que não conseguem ver o significado do que leem, simplesmente deixam de ler" (LIPMAN, 1994, p.37).

Dessa forma, segundo o autor, leituras relacionadas ao universo infantil, como os contos de fada, são capazes de revestir tais histórias de um caráter fantasioso, propiciado pela abertura "Era uma vez...", que capta a atenção da criança, ensinando-lhe não apenas a reconhecer as palavras e a aprender seu significado, mas também a identificar o sentido do vocábulo nas frases e orações, nos contextos em que aparecem. Para Bettelheim (1980, p.78), expressões como "Era uma vez, num castelo em um floresta densa e grande..." sugerem que a narrativa não irá tratar de fatos do universo real, tangível e cotidiano da criança, mas de que se afastará do mundo concreto, da realidade comum. Lipman (1994) crê que a mensagem envolvendo velhos castelos, cavernas escuras, florestas impenetráveis, quartos trancados, indicariam que algo oculto será revelado; já "Há muito tempo atrás”[sic] implicaria o conhecimento de fatos mais distantes no tempo, acionando mecanismos do universo arquetípico da criança, conduzindo-a, no final, à reflexão, que a leva à descoberta dos significados, inferindo as possibilidades lógicas do que está implícito ou subentendido" (LIPMAN, 1994, p. 38)

\section{Considerações finais}

Bettelheim (1980) aponta que, ao contar uma estória, deve ser concedido tempo para que a criança pense, analise, sinta como os elementos presentes nessa narrativa se relacionam com seu mundo, para que o conto de fada atue sobre sua psique, pois ao se estimular o confronto dessas situações arquetípicas com problemas e situações cotidianas, capazes de lhe causar perplexidade, a criança também é estimulada em seu aprendizado, compreendendo a causa, os motivos que conduziram a tais situações, induzindo-a a procurar soluções. Entretanto, como sua racionalidade ainda não exerce controle sobre seu inconsciente, "a imaginação escapa, junto com ele, sob pressão de suas emoções e conflitos não resolvidos" (Idem, p.78).

Como um dos propósitos dos contos de fada é confortar a criança, para o psicanalista, estimular a criança por meio de questionamentos acerca do que gostou 
mais ou do que não gostou na história, seria um meio de levá-la a elaborar, indiretamente, a mensagem que foi transmitida a seu próprio ego. A criança capta a mensagem que lhe foi transmitida na linguagem de símbolos - uma vez que a mente é subjetiva - porém, cujos efeitos são muito mais eficientes, uma vez que os acontecimentos reais são identificados e tornam-se importantes, devido ao significado simbólico que ela lhes atribui. Dessa forma, a mente estimula o raciocínio e o mundo arquetípico dos contos de fada colabora para criação de uma rede de conexões, que estimulam tanto a imaginação quanto a cognição da criança.

Cabe ao professor aprender a utilizar essa preciosa ferramenta de ensino que são os contos de fada, como meio de conduzir a criança ao raciocínio, estimulando o questionamento e observando, a partir do que propõe Reboul (1980), em seus trezes passos sobre a doutrinação, observar o caminho a que está se encaminhando a mente infantil, a fim de que possa realmente promover a educação dos pequenos, preparandoos para as questões mais profundas que seu intelecto possa vir a conceber, acerca do universo e de seu papel no mesmo, no âmbito filosófico.

\section{REFERÊNCIAS}

BETTELHEIM, B. A psicanálise dos contos de fadas. Rio de Janeiro, Paz e Terra, 1980.

BLOOM, H. Dumbing down American readers. Editorial. The Boston Globe, set/2003. Disponível em:

<http://archive.boston.com/news/globe/editorial_opinion/oped/articles/2003/09/24/dum bing_down_american_readers/>. Acesso em: 20 maio 2015.

BYATT, A. S. Harry Potter and the Childish Adult. The Opinion Pages. The New York Times, July, 07, 2003. Disponível em:

<http://www.nytimes.com/2003/07/07/opinion/harry-potter-and-the-childish-

adult.html>. Acesso em: 20 jul. 2017.

CAMPBELL, J. O Poder do mito. São Paulo, Palas Athena, 2012.

ELIADE, M. Mito e realidade. São Paulo, Perspectiva, 1972.

LIPMAN, M. A filosofia na sala de aula. São Paulo, Nova Alexandria, 1994.

MARTINS, Maria Angélica Seabra Rodrigues. Aprender a pensar: um desafio para a produção textual. Bauru: FAAC/Canal6, 2007.

MARTINS, Maria Angélica Seabra Rodrigues (org.). Educação, mídia e cognição. Bauru, Canal6editora, 2010. 
PENHA, J. da. Períodos filosóficos. São Paulo, Ática, 1987.

REBOUL, O. A doutrinação. São Paulo, Universidade de São Paulo, 1980.

ROWLINGS, J. K. Harry Potter e a pedra filosofal (e outros). Rio de Janeiro, Editora Rocco, 2001-2007.

SILVEIRA, N. da. Jung: vida e obra, $6^{a}$.ed. Rio de Janeiro, Paz e Terra, 1978.

SCHWARTZMAN, H. O bom professor. Coluna da Folha de S. Paulo. Disponível em: <http://www1.folha.uol.com.br/colunas/helioschwartsman/2016/05/1773190-obom-professor.shtml>. Acesso em: 20 maio 2016.

SNOOK, I. A. Doutrinação e educação. Rio de Janeiro: Zahar, 1974.

TATAR, M. Contos de fadas: edição comentada e ilustrada. Rio de Janeiro, Jorge Zahar Ltda., 2004.

VERGARA, S. C.; BRAUER, M.; GOMES, A. M. C. Z. Universidades corporativas: educação ou doutrinação? Revista de Administração Mackenzie, Ano 6, n.3, p. 167191, 2005. Disponível em: 〈http://www.redalyc.org/pdf/1954/195416195008.pdf>. Acesso em: 20 jun. 2017. ISSN:1518-6776

\section{Como referenciar este artigo}

MARTINS, Maria Angélica Seabra Rodrigues. O desenvolvimento do raciocinio na era da tecnologia: cognição $x$ doutrinação. Revista on line de Política e Gestão Educacional, Araraquara, v.2 1, n. esp. 1, p. 842-859, out./2017. Disponível em: <http://dx.doi.org/10.22633/rpge.v21.n.esp1.out.2017.10456>. ISSN: 1519-9029.

Submetido em: 10/06/2017

Aprovado em: 15/07/2017 